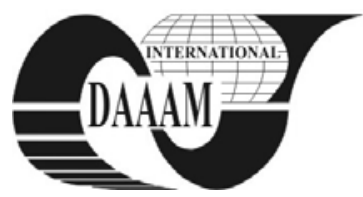

Annals of DAAAM for 2011 \& Proceedings of the 22nd International DAAAM Symposium, Volume 22, No. 1, ISSN 1726-9679 ISBN 978-3-901509-83-4, Editor B. Katalinic, Published by DAAAM International, Vienna, Austria, EU, 2011 Make Harmony between Technology and Nature, and Your Mind will Fly Free as a Bird Annals \& Proceedings of DAAAM International 2011

\title{
SYSTEM FOR MEASUREMENT, PREDICTION AND ENERGY SAVE
}

\author{
ZEZULKA, F[rantisek]; SEMBERA, J[aroslav]; VESELY, I[vo] \& SAJDL, O[ndrej]
}

\begin{abstract}
This contribution deals with a system of measurement, prediction and energy saving. The aim of the project is to develop and implement a cheap, simple system for small energy consumers to monitor and to control the energy consumption. By using information from the system, the small consumers could find a way how to save energy or how to move an energy consumption of big electrical appliances into some less expensive tariff band. The idea, principles, HW solution of system modules as well as application SW is described in the contribution
\end{abstract}

Key words: energy save, power meter, smart metering, smart grid, wi-fi

\section{INTRODUCTION}

The project of the System for measurement, prediction and energy saving is a positive response to the existing situation in energy saving and in the ubiquitous use of distributed renewable energy sources. While there are several systems for industry and for use in the big energy consumers for monitoring of energy consumption with possibility to an effective control, there is not such a system for energy save in households and by small energy consumers in general (Vesely \& Sembera, 2011).

The primary goal of the project being solved by our research group in the framework of the new Centre of research and development of renewable energy sources ( CVVOZE) of the Brno University of Technology ( BUT ) is to develop and implement the system for measurement, prediction and energy saving particularly in households or/and by small energy consumers. We pay a particular attention to develop a low price, security, user friendly and simple implemented monitoring and control system. The system concentrates its attention primarily to the electrical energy saving, but ideas, HW/SW systems and the methodology, developed in this project can be transformed for use also in systems of other energy savings. The measurement devices (system modules) will be simply implemented behind the central electro energy measurement or can be embedded directly into the sockets. Modules of the system will communicate via Internet/intranet with respect to the security principles and requirements (Beran et al., 2010).

The second reason why to develop and implement a monitoring and control system for small energy consumers deals with problems with the stability of electrical grids. The energy supply from renewable energy sources is not regular and it depends on naturals forces (sunshine, wind, water). It is not effective to stabilize such an electrical grid with renewable as well as classical power stations by controlling of traditional power plants. Much more effective would be to control the grid stability by controlling of a lot of small energy consumers. It is a task for energy producers and distributors to realize a more sophisticated price strategy. It should come from the idea, that in hours of energy overflow (sunshine, wind), the price should be low, in days and hours of low energy production from FV power plants and/or wind power plants, the energy price should be higher. The positive reaction of a lot of small consumers will be a logical consequence in case, that there will be information about energy consumption and energy overflow/lack forecast available for small energy consumers. The proposed system is designed with these aspects. Such information and control system is named „the smart metering system“. It enables monitoring of the energy consumption and will suggest small consumers what and when to connect or disconnect the main electrical appliances (http://www.esmig.eu).

\section{HW SOLUTION OF THE SYSTEM FOR MEASUREMENT, PREDICTION AND ENERGY SAVING}

A block diagram of the system for measurement, prediction and energy save is described in the Fig. 1.

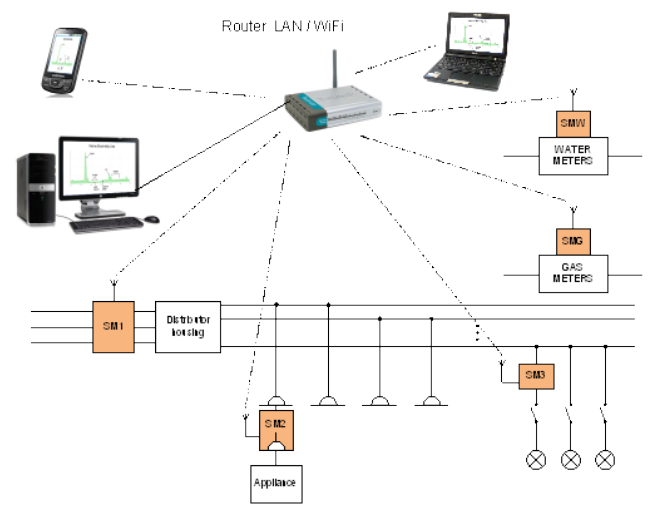

Fig. 1. Block diagram of SMPSE

The system SMPSE supposes two types of energy monitoring. The first one assumes the only one central measurement device (SM1) in front of the consumer internal electrical grid. This device measures and checks all the energy consumption of a flat, house and building. By means of a sophisticated SW for the signal analyses of measured signals of the common current (energy) can be identified each of connected electric devices. The second type of energy monitoring assumes, that by means of embedded electronic (SM2) into particular sockets, the work of the main electrical appliances in a flat, house, building can be identified and controlled (connected or disconnected), depends on the control strategy. The standard connections of modules SM2 with the central SM1 as well as the connection of the SM1 with a monitoring and control station assumes to be Internet/intranet.

The Internet monitoring and control is assumed to be developed and the design of the whole system guaranties all security requirements (Sveda et al., 2005). Primarily the main or the only communication will be done in the home/ institution intranet only, because the system is primarily intended for the monitoring and control inside the buildings of small energy consumers (Zezulka \& Beran, 2008). Both the modules SM 1 and SM 2 will be equipped by an Ethernet communication unit, 
but in the one of the first phases of the system SMPSE implementation, there will be also developed a power line communication unit for users without Wi-Fi communication unit (Zezulka et al., 2010).

\subsection{The central module SM 1}

The central module SM1 will be situated behind the electric meter into the main electrical distributor and will monitor the common consumption of the electrical energy of the small energy consumer. The module SM1 will be supplied directly from the main electrical grid. The principal scheme of the SM1 is in the Fig. 2.

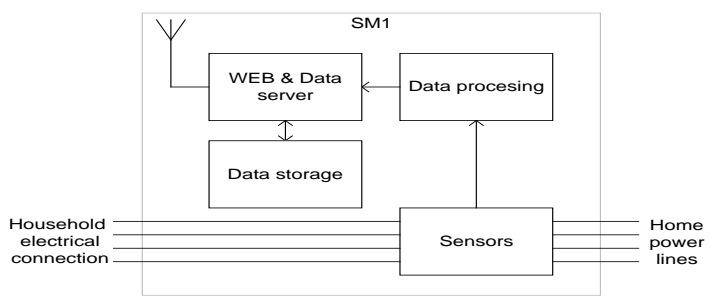

Fig. 2. Block scheme of the SM1

The measured value -current - will be measured by a clamp ammeter or directly via a current input of the SM1 which will be connected in the fiber terminal strip which will be subordinated to the internal electrical grid. The voltage from the main electric meter will be measured directly by a voltage input of the SM 1. In order to guarantee the low cost of the system, the SM1 has no display and the measured information (energy in Watt hours) will be processed in the SM 1 and will be sent to the master/gateway to the supervisor (local PC connected to the intranet of the building/house/institution, or a stand alone gateway intranet/internet).

From the mechanical point of view, the module SM1 will be constructed for the DIN $35 \mathrm{~mm}$ toolbar with cable bushings until approximately 0.5 meter to connect to measured cables.

\subsection{The embedded module SM2}

The device SM2 will be designed for monitoring, measurement and control of one phase line into the house. It can be embedded into any electric socket. It will measure the power consumption of appliances connected in the receptacle. The SM2 will communicate with the supervisor's PC or SM1 via Wi-Fi or via power line. The device SM2 embedded into an electrical receptacle enables not just monitoring of the energy consumption but also enables a simple and specific control (on/ off switching) of any electrical appliance in any time. The monitoring of the energy consumption of any appliance will be more precise than the monitoring by means of the SM1. Anyway both the SM1 and SM2s enable the consumer to dynamically economize the energy consumption corresponding to the changes of energy costs.

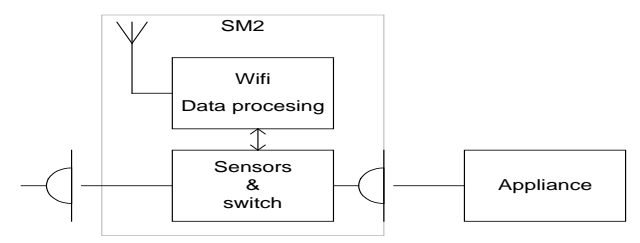

Fig. 3. Block scheme of the SM2

While the lights, TV sets, radios, videos and other electric and electronic appliances including electric ovens, electric kettles etc. have to operate in any time of necessity, electric direct heating, electric water boiler, electric washing machine, electric dryer and some other main electric appliances can be disconnected in the time of a lack of energy from renewable energy sources and switched on in time of the energy overflow and corresponding low price of energy. This equipment enables stabilization of the electrical grid by means of a common intelligent consumption strategy of a lot of small energy consumers. The idea demonstrates an effective cooperation of smart grid and smart metering. See Fig. 3. for the block diagram of the SM2.

\section{USER SOFTWARE FOR DATA PROCESSING}

Measured data will be stored in memory of SM1 and SM2. The memory of the devices will be limited. The user SW will transfer periodically data from SM1 and SM2 into the central supervisor's PC or a master unit. The user SW will also help users to optimize their control strategy of the main electic appliances to minimize the invoice for energy consumption.

\section{CONCLUSION}

The contribution deals with System for measurement, prediction and energy saving in households and in institutions of small energy consumers. The idea of the system is described in the principal block diagram which shows synergy of three principal elements of the system, the module SM 1 for monitoring the whole energy consumption, as well as the module SM 2 for direct monitoring and control of the main electrical appliances. It also shows the communication subsystem (mostly wireless), which enables the common smart utilization of the information from energy-meters and from the prediction subsystem to the supervisor's decision system. By the combination with a smart dynamic tariff band the proposed smart metering system enables not only the save of electrical energy, but it also supports mechanisms to stabilize the electrical grid., That contains classical as well as renewable energy sources. The system offers a new method and instrumentation to stabilize the grid by available decision of a lot of individual small energy consumers instead of the stabilization by a control of classical electrical power sources.

\section{ACKNOWLEDGEMENTS}

This work was supported by Operational Program Research and Development for Innovations; project CVVOZE - Center for Research and Utilization of Renewable Energy Sources, no. of contract CZ.1.05/2.1.00/01.0014.

\section{REFERENCES}

Beran, J.; Fiedler, P.; Zezulka, F. (2010). Virtual Automation Networks. IEEE industrialelectronics magazine, Vol. 4, No. 3, pp. 20-27, ISSN 1932- 4529

Zezulka, F.; Beran, J. (2008). Virtual Automation Networks Architectural Principles and the Current State of Development. In Proceedings of the 34th Annual Conference of the IEEE Industrial Electronics Society, Orlando, Florida, ISBN 978-1-4244-1767-4, Chow, M.-Y. (Ed.), pp. 1545-1550, University of Florida, Orlando

Veselý, I.; Šembera, J. (2011). Kogenerační jednotky v síti Smart grid. In Proceedings of the 5th Annual Conference of Výsledky výzkumu, vývoje a inovací pro obnovitelné zdroje. Kouty nad Desnou Czech Republic, April, 2011, ISBN978-80-85990-18-8, CEMC (Ed.), Praha 10

Švéda, M.; Beneš, P.; Vrba, R.; Zezulka, F. (2005). Industrial sensor network, In: Handbook of Sensor Networks. editors: M. Ilyas, I. Mahgoub, pp. 251 - 276, CRC Press, ISBN 08493-1968-4, London

*** (2011) http://www.esmig.eu - European Smart Metering Industry Group, Smart Metering for Europe, Accessed on: 2011-07-16 